Int. J. Electrochem. Sci., 16 (2021) Article ID: 210216

International Journal of

ELECTROCHEMICAL

SCIENCE

www.electrochemsci.org

\title{
Electrochemical Determination of Chloramphenicol based on ZnO-NPs/SWCNTS Composite modified glassy carbon electrode
}

\author{
Wei Wang ${ }^{1, *}$, De Sun ${ }^{2}$ \\ ${ }^{1}$ Department of Pharmaceutical Engineering, College of Humanities \& Information Changchun \\ University of Technology, Changchun, Jilin 130122, China \\ ${ }^{2}$ Department of Chemical Engineering, Changchun University of Technology, Changchun, Jilin \\ 130012, China \\ *E-mail: wangweiccutchi@163.com
}

doi: $10.20964 / 2021.02 .49$

Received: 14 September 2020 / Accepted: 26 November 2020 / Published: 31 December 2020

This paper was focused on studying the electrochemical properties of Zinc Oxide nanoparticles ( $\mathrm{ZnO}$ NPs)/SWCNTs/glassy carbon electrode (GCE) to determine chloramphenicol (CAP) through voltammetric techniques. ZnO NPs/SWCNTs composite was synthesized using sol-gel technique for modification of GCE surface. The morphology and structure of ZnO NPs/SWCNTs was studied by FESEM and XRD analyses. The results indicated that the ZnO NPs were successfully synthesized in wurtzite hexagonal structure on SWCNTs structure. Electrochemical results revealed that $\mathrm{ZnO}$ NPs/SWCNTs/GCE possess high stability, selectivity and repeatability response for determination of CAP. The wide linear range, high sensitivity and low detection limit for CAP detection were $10 \mu \mathrm{M}-140$ $\mu \mathrm{M}, 1.65931 \mu \mathrm{A} / \mu \mathrm{M}$ and $0.03 \mu \mathrm{M}$, respectively. Determination of CAP by ZnO NPs/SWCNTs/GCE sensor in eye drops showed that it can bea suitable choice for practical detection of CAP in real samples.

Keywords: Chloramphenicol; ZnO NPs/SWCNTs composite; Electrochemical sensor; Voltammetric techniques

\section{$\underline{\text { FULL TEXT }}$}

(C) 2021 The Authors. Published by ESG (www.electrochemsci.org). This article is an open access article distributed under the terms and conditions of the Creative Commons Attribution license (http://creativecommons.org/licenses/by/4.0/). 